\title{
Nasal carriage of Staphylococcus aureus among a healthy suburban population: genotypic diversity and frequency of pathogenicity genes
}

\begin{abstract}
We analyzed the frequency and genotypic diversity of Staphylococcus aureus nasal carriage in a healthy suburban population in the state of New Jersey, United States of America, from 2011 to 2018, and the presence of virulence and antibiotic resistance genes. A total of 77 isolates were analyzed by phenotypic tests and PCR testing using genes coding for $S$. aureus $16 \mathrm{~S}$ rRNA, methicillin resistant ( $m e c A)$, vancomycin resistant (vanA), tetracycline resistant (tet $M)$, macrolide resistant (ermA), Panton Valentine Leukocidin (lukF), arginine catabolic element (ACME), enterotoxin A (sea), staphylococcal protein A (spa), and toxic shock syndrome (tst). Percentage of nasal carriers of $S$. aureus was $11 \%$ and $3 \%$ for MRSA. Based upon spa gene typing, 41 different genotypes were found. The most common types were $\mathrm{t} 008, \mathrm{t} 012$, and $\mathrm{t} 363$. Frequencies in $S$. aureus for spa and ACME genes were $100 \%$ and $62 \%$. However, percentages for sea, tst, and $l u k F$ genes were $38 \%, 27 \%$ and $22 \%$, respectively. The ermA and tet $M$ were detected in $57 \%$ and $13 \%$ of isolates. None of the mecA positive isolates showed the presence of vanA. Staphylococcal cassette chromosome (SCC) mec typing was performed using a multiplex PCR. SCC mec type IV was the most common among all MRSA isolates. In conclusion, healthy individuals carried a genetically diverse population of $S$. aureus with different virulence and antibiotic resistance genes in the nasal cavities representing an unrecognized and understudy human reservoir for antimicrobial resistance and genotypic diversity.
\end{abstract}

Volume 9 Issue 5 - 202 I

\author{
Luis Jimenez, Sibora Peca, Joy Bochis, Jenifer \\ Vasquez, Stephanie Zapata, Rozan Ramadan, \\ Matthew Gardner, Stephanie Perez, Arianna \\ Pinto, Lisa Pincus, Kadiatou Fadiga, and \\ Adelajda Turku \\ Biology and Horticulture Department, Bergen Community \\ College, USA
}

\begin{abstract}
Correspondence: Luis Jimenez, Biology and Horticulture Department, 400 Paramus Road, Paramus, New Jersey 07563, Email ljimenez@bergen.edu
\end{abstract}

Received:September 28, 2021 | Published: October 25, 2021

Keywords: Staphylococcus aureus, nasal carriage, pathogenicity genes, antimicrobial resistance genes, PCR, genotypic diversity

\section{Introduction}

Infections by Staphylococcus aureus are the number one cause for nosocomial outbreaks in the United States. ${ }^{1} S$. aureus is responsible for causing a variety of diseases such as skin eruptions, bacteremia, endocarditis, toxic shock syndrome, and pneumonia. However, S. aureus is also part of the commensal microflora of the anterior nares in some humans. ${ }^{2}$ Most carriers are not infected by the bacteria but are reservoirs assisting the spreading of $S$. aureus through the community. ${ }^{3-5}$ Furthermore, nasal carriage is associated with endogenous infections and can increase the risk of nosocomial infections. Nasal carriage is influenced by a wide variety of host and bacterial factors. ${ }^{6}$ The distinction between colonization and infection is critical. ${ }^{7}$ Colonization is the presence of $S$. aureus without signs or illness or infection. Infection presents clinical signs of illness and inflammation. Determination of the frequency of $S$. aureus nasal carriage in healthy populations may lead to a better understanding of the risk factors associated with infections and the distribution of different genotypes and virulence genes. For instance, nasal carriage was shown to be an important factor in bacteremia and other diseases while elimination of $S$. aureus from nasal cavities reduced infection rates.

The pathogenic ability and adaptability of $S$. aureus to cause multiple diseases is due to the presence of a wide variety of extracellular toxins such as enterotoxins, toxic shock syndrome (TSS), hemolysins, leukocidins (Panton Valentine (PVL), and coagulase. ${ }^{8,9}$ This ability is further enhanced by the presence of the arginine catabolic element (ACME) and staphylococcal protein A (spa) genes. ${ }^{10,11}$ The ACME genes allow the dissemination of $S$. aureus from human skin to other parts of the body while spa genes prevent phagocytosis by white blood cells.

Antibiotic resistance is also a major factor contributing to the survival and difficulty of controlling $S$. aureus infections in human populations. The intrinsic resistance to antibiotics such as methicillin and other beta-lactam antibiotics is driven by the presence of the $m e c \mathrm{~A}$ gene. ${ }^{12}$ The confirmation of the presence of the mecA gene is the benchmark to diagnose methicillin-resistant $S$. aureus (MRSA) in hospital infections. ${ }^{13}$ The mecA gene codes for methicillin resistant by the action of a penicillin binding protein $2 \mathrm{a}$ (PBP2a). The mecA gene is within the mobile genetic element staphylococcal cassette chromosome mec (SCCmec) that inserts site-specifically intro the staphylococcal chromosome.

Other antibiotics such as tetracycline and macrolides are commonly used to treat $S$. aureus and MRSA infections. ${ }^{3}$ However, resistant strains have been isolated from clinical and environmental samples. Because of the resistance to different types of antibiotics, MRSA infections in hospital environments are difficult to treat. In some situations, the only antibiotic available for treatment is vancomycin. However, vancomycin resistant is slowly becoming a serious problem in healthcare facilities.

MRSA infections in health care environments such as hospitals, nursing homes, etc. are mostly caused by health-care associated strains (HA-MRSA), ${ }^{79}$ Patients with HA-MRSA infections were usually due to recent hospitalization, surgery, dialysis, indwelling medical devices, or living in nursing homes. Community-associated MRSA (CA-MRSA) infections were related to patients that did not have a history of recent hospitalization nor had any of the risk factors 
associated to HA-MRSA. CA-MRSA strains usually have a higher frequency of leukocidin genes and a different SCCmec element, predominantly type IV or V. Few studies have been performed to ascertain the frequency of nasal carriers of methicillin-susceptible $S$. aureus (MSSA) and MRSA and the distribution of virulence genes in healthy suburban populations in the United States.

The major objective of this study was to determine the numbers of nasal carriers of MSSA and MRSA and the presence of genes that enhance pathogenicity, adaptability, and survival of $S$. aureus in a healthy suburban population.

\section{Materials and methods}

\section{Study population}

Seven hundred nine healthy individuals living in the suburbs of the state of New Jersey, United States of America, were included in this study that lasted from 2011 to 2018. Informed consent was obtained from all people participating in the study.

\section{Phenotypic analysis}

Nasal swab samples from one nostril were streaked on mannitol salt agar (MSA). The plates were incubated at $35^{\circ} \mathrm{C}$ for 48 hours. After incubation, all colonies showing mannitol fermentation (yellow colonies) were analyzed by using the Gram staining reaction, blood hemolysis on blood agar, catalase test, and the tube coagulase test. $S$. aureus WS obtained from Ward Scientific (www.wardsci.com) was used as a quality control strain for all tests.

\section{DNA extractions}

Chromosomal DNA extractions were performed from each isolate as previously described. ${ }^{14}$ Different aliquots of DNA were used in the $\mathrm{PCR}$ reactions.

\section{Genetic identification of S. aureus isolates}

Genetic identification of $S$. aureus isolates was performed by using 16S rRNA gene specific $S$. aureus DNA primers as previously described..$^{15}$ The PCR reaction conditions were, an initial denaturation at $94^{\circ} \mathrm{C}$ for $1 \mathrm{~min}$ followed by 30 cycles of amplification (denaturation at $94^{\circ} \mathrm{C}$ for $1 \mathrm{~min}$, annealing at $65^{\circ} \mathrm{C}$ for $3 \mathrm{~min}$, and extension at $72 \mathrm{C}$ for $2 \mathrm{~min}$ ) ending with a final extension of $72^{\circ} \mathrm{C}$ for $5 \mathrm{~min}$. A positive reaction was indicated by the presence of a 273-base pair (bp) DNA fragment.

\section{PCR detection of pathogenicity and antibiotic resistant genes}

DNA primers to detect the presence of toxic shock syndrome genes (tst) were previously described. ${ }^{8}$ The PCR reaction conditions were, an initial denaturation at $94^{\circ} \mathrm{C}$ for 5 min followed by 35 cycles of amplification (denaturation at $94^{\circ} \mathrm{C}$ for $1 \mathrm{~min}$, annealing at $57^{\circ} \mathrm{C}$ for $1 \mathrm{~min}$, and extension at $72^{\circ} \mathrm{C}$ for $1 \mathrm{~min}$ ) ending with a final extension of $72^{\circ} \mathrm{C}$ for $7 \mathrm{~min}$. A positive reaction was indicated by the presence of a 326bp DNA fragment. Enterotoxin A genes (sea) were analyzed by using DNA primers previously described. ${ }^{8}$ The PCR reaction conditions were, an initial denaturation at $94^{\circ} \mathrm{C}$ for $5 \mathrm{~min}$ followed by 35 cycles of amplification (denaturation at $94^{\circ} \mathrm{C}$ for $2 \mathrm{~min}$, annealing at $57^{\circ} \mathrm{C}$ for $2 \mathrm{~min}$, and extension at $72 \mathrm{C}$ for $1 \mathrm{~min}$ ) ending with a final extension of $72^{\circ} \mathrm{C}$ for $7 \mathrm{~min}$. A positive reaction was indicated by the presence of a $102 \mathrm{bp}$ DNA fragment. Arginine catabolic mobile element (ACME-encoded) $\operatorname{arcA}$ gene was analyzed by using specific primers previously described. ${ }^{10}$ The PCR reaction conditions were, an initial denaturation at $95^{\circ} \mathrm{C}$ for 5 min followed by 30 cycles of amplification (denaturation at $95^{\circ} \mathrm{C}$ for $1 \mathrm{~min}$, annealing at $50^{\circ} \mathrm{C}$ for 1 min, and extension at $72 \mathrm{C}$ for $2 \mathrm{~min}$ ) ending with a final extension of $72^{\circ} \mathrm{C}$ for $5 \mathrm{~min}$. A positive reaction was indicated by the presence of a $624 \mathrm{bp}$ DNA fragment.

Staphylococcal Protein A (spa), mecA, and leucocidin $(l u k F)$ genes were amplified using DNA primers as previously described. ${ }^{12}$ The PCR reaction conditions were, an initial denaturation at $94^{\circ} \mathrm{C}$ for 5 min followed by 30 cycles of amplification (denaturation at $94^{\circ} \mathrm{C}$ for $30 \mathrm{sec}$, annealing at $59^{\circ} \mathrm{C}$ for $1 \mathrm{~min}$, and extension at $72^{\circ} \mathrm{C}$ for $1 \mathrm{~min}$ ) ending with a final extension of $72^{\circ} \mathrm{C}$ for $10 \mathrm{~min}$. Positive reactions for $l u k F$, and mecA genes were indicated by the presence of DNA fragments of $85 \mathrm{bp}$ and $162 \mathrm{bp}$, respectively. $S p a$ gene detection was indicated by DNA fragments ranging from 180 to $600 \mathrm{bp}$. Vancomycin resistant genes (vanA) were analyzed by using DNA primers described by Azimian et al. ${ }^{16}$ The PCR reaction conditions were, an initial denaturation at $94^{\circ} \mathrm{C}$ for 5 min followed by 40 cycles of amplification (denaturation at $94^{\circ} \mathrm{C}$ for $1 \mathrm{~min}$, annealing at $55^{\circ} \mathrm{C}$ for 1 min, and extension at $72^{\circ} \mathrm{C}$ for $2 \mathrm{~min}$ ) ending with a final extension of $72^{\circ} \mathrm{C}$ for $5 \mathrm{~min}$. A positive reaction was indicated by the presence of a $713 \mathrm{bp}$ DNA fragment. Tetracycline, tet $M$, and macrolide resistant, ermA, genes were analyzed using primers described by Strommenger et al. ${ }^{17}$ The reaction conditions were $94^{\circ} \mathrm{C}$ for 3 min followed by 35 cycles of $94^{\circ} \mathrm{C}$ for $30 \mathrm{sec}, 55^{\circ} \mathrm{C}$ for $30 \mathrm{sec}, 72^{\circ} \mathrm{C}$ for $1 \mathrm{~min}$, with a final extension of $72^{\circ} \mathrm{C}$ for $7 \mathrm{~min}$. Positive reactions were indicated by the amplification of $158 \mathrm{bp}$ and $190 \mathrm{bp}$ fragments for tetM and ermA, respectively.

\section{DNA sequencing}

Sequencing of the amplified PCR fragments from bacterial isolates were performed by Genewiz, LLC (South Plainfield, New Jersey). Homology searches were performed using the GenBank server of the National Center for Biotechnology Information (NCBI) (http://blast. ncbi.nlm.nih.gov/Blast.cgi) and the BLAST algorithm. ${ }^{18}$

\section{Spa typing}

The polymorphic $\mathrm{X}$ region of the spa gene was amplified from all $S$. aureus isolates as described above. All sequencing reactions were performed by Genewiz LLC (South Plainfield, New Jersey). Homology searches were performed using the GenBank server and the BLAST algorithm. Spa types were assigned by using the Bionumerics software application version 7.6.3 (Applied Maths Inc., Austin, TX), (Applied Maths NV Sint-Martens-Latem, Belgium) installed in a windows computer. ${ }^{19}$

\section{SCCmec typing}

Typing of the SCCmec genetic element was performed using a multiplex PCR assay described by Boyle et al. ${ }^{20}$ Amplification conditions comprised $4 \mathrm{~min}$ at $94^{\circ} \mathrm{C}$, followed by 30 cycles of $94^{\circ} \mathrm{C}$ for $30 \mathrm{sec}, 55^{\circ} \mathrm{C}$ for $30 \mathrm{sec}, 72^{\circ} \mathrm{C}$ for $1 \mathrm{~min}$, with a final extension of $4 \mathrm{~min}$ at $72^{\circ} \mathrm{C}$. The SCCmec type was determined on the basis on the band pattern previously described. ${ }^{20}$

\section{Results}

\section{Characterization of S. aureus isolates by phenotypic analysis}

A total of 77 isolates were described and identified as $S$. aureus from nasal cavities of 709 healthy individuals. All isolates and the control strain were gram positive cocci, fermented mannitol, produced coagulase, and showed beta-hemolytic reactions on blood agar. 


\section{Identification of $S$. aureus by I6S rRNA analysis}

Genetic analysis using 16S rRNA primers confirmed the presence of the specific $273 \mathrm{bp} \mathrm{S}$. aureus 16S rRNA fragment (Figure 1). All 77 isolates and the control strain showed a positive reaction with no other DNA fragments detected. After genetic identification was completed, the nasal carriage for S. aureus was calculated to be $11 \%$.

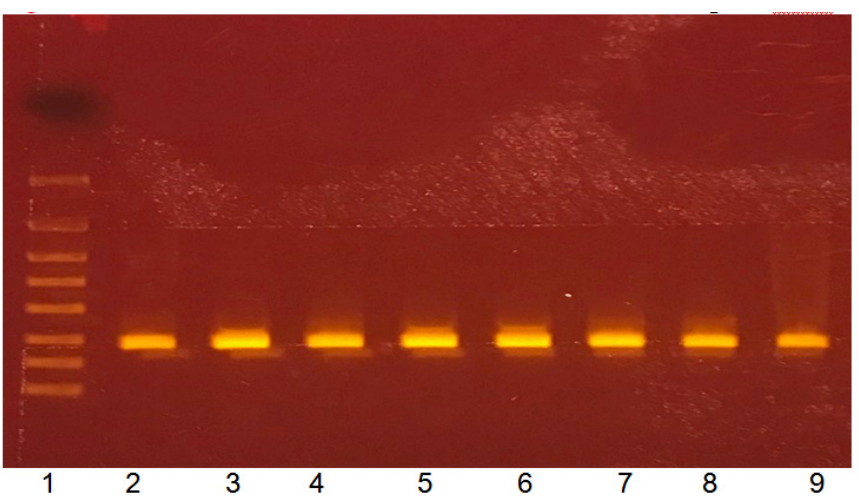

Figure I Genetic identification of human S. aureus nasal isolates using I6S rRNA sequences.

Lanes:

Lane I: Molecular weight marker, bp (from top to bottom, 4000, 2000, I250, $800,500,300,200,100)$

Lane 2: S. aureus 57

Lane 3: S. aureus 58

Lane 4: S. aureus 59

Lane 5: S. aureus 60

Lane 6: S. aureus 6I

Lane 7: S. aureus 62

Lane 8: S. aureus 63

Lane 9: S. aureus 64

\section{Detection of antibiotic resistance genes}

The presence of the mecA gene, indicated that $23 \%$ of the isolates were MRSA (Figure 2a). MRSA carriage was identified in $3 \%$ of the people tested. Seventy seven percent of the isolates did not carry the $m e c A$ gene. None of the $m e c A$ isolates showed a positive reaction for the presence of the vanA gene. The ermA and tet $M$ genes were found in $57 \%$ and $13 \%$ of the $S$. aureus isolates. When comparing MRSA and MSSA, higher frequency of tetM genes were found in MSSA while ermA was found to be more predominant in MRSA strains (Figure 2b).

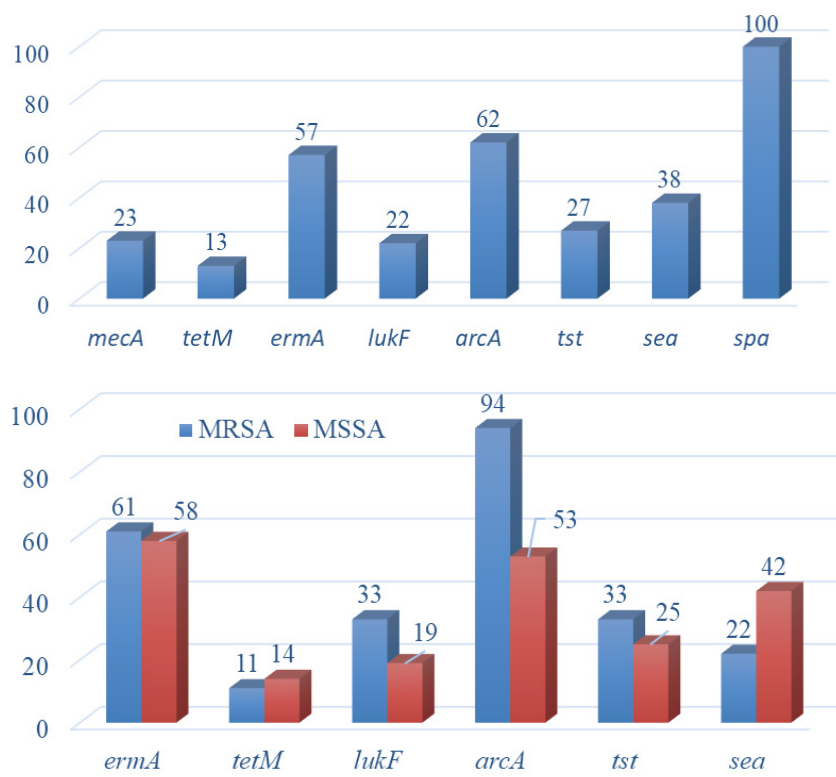

Figure 2 Frequency of pathogenicity genes.

a. Percent of positive in $\mathrm{S}$. aureus population. $\mathrm{N}=77$.

b. Percent of positive in MRSA $(n=18)$ and MSSA negative $(n=59)$ population.

\section{Characterization of S. aureus isolates by molecular typing techniques}

SCCmec typing of MRSA isolates demonstrated that $83 \%$ contained a type IV cassette on the chromosome (Table 1). There were other two SCCmec types detected. Those were type I (6\%) and III $(11 \%)$.

Table I I6S rRNA, SSCmec, and spa typing with pathogenicity gene results for MRSA isolates

\begin{tabular}{llllllllll}
\hline Isolate & I6S rRNA & SSCmec Type & spa Type & lukF & ACME & tst & sea & tetM & ermA \\
\hline Sal7 & + & IV & t304 & - & + & - & - & - & + \\
Sa25 & + & IV & t3380 & - & + & + & + & + & - \\
Sa3I & + & IV & t316 & - & + & - & - & - & - \\
Sa33 & + & IV & t216 & - & + & - & - & - & + \\
Sa35 & + & I & t495I & + & + & - & - & - & + \\
Sa37 & + & IV & t443 & + & + & - & - & - & + \\
Sa38 & + & IV & t062 & + & + & + & - & - & - \\
Sa4I & + & IV & t443 & - & + & - & - & - & - \\
Sa43 & + & IV & t216 & - & + & + & - & - & - \\
Sa45 & + & III & U* & - & - & + & - & - & - \\
Sa48 & + & IV & t008 & + & + & - & - & - & - \\
\hline
\end{tabular}


Table Continued...

\begin{tabular}{|c|c|c|c|c|c|c|c|c|c|}
\hline Isolate & I6S rRNA & SSCmec Type & spa Type & lukF & ACME & tst & sea & tetM & ermA \\
\hline $\mathrm{Sa} 50$ & + & IV & $\mathrm{t} 334$ & - & + & + & + & - & + \\
\hline Sa5I & + & IV & t05I & - & + & - & + & - & + \\
\hline $\mathrm{Sa} 53$ & + & IV & $U^{*}$ & + & + & - & + & + & + \\
\hline $\mathrm{Sa} 55$ & + & IV & $\mathrm{t} 240$ & - & + & - & - & - & + \\
\hline $\mathrm{Sa} 56$ & + & IV & $\mathrm{U}^{*}$ & - & + & - & - & - & + \\
\hline Sa76 & + & III & t359 & + & + & + & + & - & + \\
\hline Sa77 & + & IV & $\mathrm{t}|4| 4$ & - & + & - & - & - & + \\
\hline
\end{tabular}

U*=Unknown

All 77 isolates showed the presence of the spa gene (Figure 2a). Typing of the spa gene yielded 41 different genotypes (Table 2). The most common genotypes were t008 ( $n=4)$, t012 ( $n=4)$, t021 ( $n=3)$, t338 $(n=3), t 363(n=4)$, and t443 $(n=3)$. All other genotypes had 1 or 2 strains. There were 15 isolates that did not belong to any spa type. The most common genotype among MRSA strains was $t 443$ (Sa37, Sa41). Two genotypes t012 (Sa40, Sa44, Sa67, Sa72) and t363 (Sa2, Sa16, $\mathrm{Sa} 22, \mathrm{Sa} 58)$ were the most common with MSSA strains.

Table 2 List of spa-types and number of isolates ( $\mathrm{n}$ )

\begin{tabular}{|c|c|}
\hline \multirow[t]{2}{*}{ Most frequent spa-types } & $\mathrm{t} 008, \mathrm{t} 0 \mid 2, \mathrm{t} 363,(\mathrm{all} n=4)$ \\
\hline & t02I, t338, t443, (all n=3) \\
\hline \multirow[t]{3}{*}{ Other spa-types } & $\mathrm{t} 002, \mathrm{t} 024, \mathrm{t} 209, \mathrm{t} 216, \mathrm{t} 316, \mathrm{t} 334, \mathrm{t} 57 \mathrm{I}(\mathrm{all} \mathrm{n}=2)$ \\
\hline & 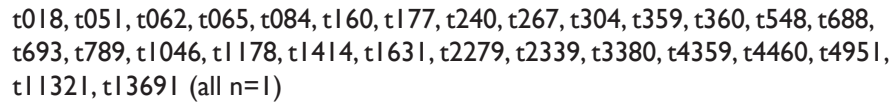 \\
\hline & Spa-types not in database $(n=15)$ \\
\hline
\end{tabular}

\section{Detection of virulence genes in S. aureus isolates}

Sixty two percent of the $S$. aureus isolates from nasal samples showed the presence of the ACME gene (Figure 2a). Sea genes showed a frequency of $38 \%$ while $t s t$ and $l u k F$ genes showed $27 \%$ and $22 \%$, respectively (Figure 2a). Only $27 \%$ of the MRSA strains with a type IV SCCmec cassette showed the presence of $l u k F$ genes. The ACME gene was found in all SCCmec type I and IV strains. However, it was not detected in one of the type III isolates (Table 1). Twenty nine percent of SCCmec type IV strains showed the presence of tst and sea genes.

Genes for colonization (ACME), toxic shock syndrome (tst), and leucocidin production $(l u k F)$ were found to have higher frequency in MRSA than in MSSA (Figure 2b). Only sea genes showed higher percentages with MSSA than with MRSA while spa gene percentages were similar for MRSA and MSSA. When analyzing the numbers of antimicrobial resistant and virulence genes, 39\% of MRSA isolates showed the presence of at least 4 of those genes while $22 \%$ of those isolates showed 5 genes. When compared to MRSA, 17\% of MSSA isolates showed the presence of 4 genes and $10 \%$ with 5 genes.

\section{Discussion}

Nasal carriage of $S$. aureus may represent a significant risk for invasive infection in susceptible populations. The people sampled in this study were healthy with no signs or symptoms of skin, respiratory, sinus, or throat infections. S. aureus nasal carriage in the present study was found to be $11 \%$. Previous studies in the USA showed a $35 \%$ carriage rate but that study was done by sampling both nostrils ${ }^{2}$. However, in this study we only sampled one nostril which might have underestimated the numbers of carriers. Higher percentages of $S$. aureus carriers were reported in Iran, $20.8 \%,{ }^{4}$ China, 15.4\%, ${ }^{3}$ India, $12 \%,{ }^{21}$ Ghana, 22.1\%, ${ }^{22}$ and Brazil, 31.1\%. ${ }^{23}$ In general, the colonization rate of $S$. aureus in healthy individuals through the world ranges from 3 to $70 \% .{ }^{24}$ However, several factors can have predisposed nasal carriage. Age, gender, health, and chronic diseases are among the factors considered to increase nasal carriage. The environment can also be a reservoir for S. aureus. Environmental contamination with $S$. aureus was reported where MSSA were recovered from environmental surfaces. ${ }^{25}$ In that study $28 \%$ of the people sampled were found to be $S$. aureus carriers.

Previous studies reported MRSA carriage values very similar to the values found in this study (3\%). Kildow et al., ${ }^{2}$ reported a $3.2 \%$ carriage rate when samples from both nostrils were analyzed. Similar percentages of MRSA carriers were found in China. ${ }^{3}$ Higher percentages of MRSA carriers were reported in India ${ }^{21}$ and New Zealand (5\%). ${ }^{26}$ A U.S. population survey reported the rate of colonization of $S$. aureus and MRSA in the USA ranged from $31.6 \%$ to $0.84 \%{ }^{1}$ Evidently $S$. aureus and MRSA carriers varied significantly even within similar populations in the same countries. A major limitation of our study was the sampling of only one nostril which might have underestimated the carriage rate for MRSA.

SCCmec typing results for MRSA isolates indicated the predominant presence of a type IV cassette. SCCmec is a genetic element involved in the horizontal transfer of resistant genes that has been used as a marker for distinguishing between HA-MRSA and CA-MRSA. ${ }^{13}$ Type IV is mostly associated to CA-MRSA strains. ${ }^{13,27}$ HA-MRSA are commonly associated to types I-III. In our study $83 \%$ of MRSA strains belonged to type IV SCCmec while healthy carriers in Mexico were found to have a lower percentage of type IV strains, $21.4 \%{ }^{28}$ Studies of clinical isolates from community health centers in 
the New York (NY) city area showed that most infections were related to CA-MRSA containing type IV SCCmec elements. ${ }^{29}$ Most isolates belonged to the USA300 clone (t008, SCCmecIV, PVL+, AMCE+) or to closely related clones showing different spa and SCCmec types without the presence of PVL or ACME genes. Strain USA300 is the predominant MRSA clone in North America. Nasal MRSA isolates showed $84 \%$ of PVL. In this study only 1 isolate, Sa48, showed the typical USA300 clone profile. However, 3 MSSA isolates, Sa6, Sa7, and Sa18 were found to belong to the t008 spa-type but showed a negative reaction for $m e c A$, ACME and PVL. Environmental contamination of surfaces in households in NY city and nursing homes in Ohio were reported to be major reservoirs for USA300 dissemination, infection, and diversification. ${ }^{30,31}$ However, we did not carry any environmental sampling during this study. A year after our study was completed, surfaces were sampled from different locations but no $S$. aureus or MRSA were isolated.

None of the MRSA isolates showed the presence of the vanA gene indicating their possible sensitivity to the antibiotic vancomycin. Vancomycin continues to be the most common antibiotic for MRSA infections when other antibiotics are inefective. However, genes coding for macrolide and tetracycline resistance were detected. Previous studies showed higher percentages of tet $M$ genes in MRSA isolates from European clinical samples. ${ }^{17}$ Resistant to the tetracycline by the tet $M$ gene is mediated by a non-covalent modification of the ribosomes during protein synthesis. The frequency of tet $M$ genes in MRSA isolates from those samples was $29 \%$ while in this study we found lower values, $11 \%$. MRSA isolates from burn unit patients in Iran also showed higher percentages of tet $M$ genes, $32.4 \% .{ }^{32}$ However, when it came to macrolide resistance genes higher percentages were found in this study, $61 \%$, than previously reported for clinical isolates, $57 \% .{ }^{17}$ Other studies in France showed slightly higher frequencies in clinical isolates of $S$. aureus, $63.2 \% .{ }^{33}$ Only $57 \%$ of the $S$. aureus isolates in this study showed the presence of the ermA gene. The ermA gene codes for methylases that add methyl groups to the adenine residue at position 2085 in $23 \mathrm{~S}$ rRNA, resulting in the significant reduction in the bonding between ribosomes and macrolide antibiotics. Clinical isolates from China showed $21.6 \%$ of MRSA strains containing erm $A$ genes while MSSA showed a lower frequency, $11.1 \% .^{34}$ The same study found that MRSA isolates showed higher frequencies of tetM, $67.1 \%$, than MSSA, $59.3 \%$.

PVL genes are strongly associated with skin infections, soft tissue infections, and severe necrotizing pneumonia. They destroy white blood cells such as neutrophils and macrophages and promotes tissue necrosis. In this study, PVL genes were found in $22 \%$ of $S$. aureus isolates which was higher than studies from Indonesia $(10 \%)^{35}$ and Iran (20\%). ${ }^{4}$ However, higher prevalence of PVL genes were reported in New Zealand with $31 \%{ }^{26}$ They found similar percentages of PVL genes in clinical and nasal isolates. S. aureus isolates in Ghana were found to have much higher PVL prevalence, 58\%. ${ }^{22}$ Studies in a New York prison found $93 \%$ isolates carrying PVL genes. ${ }^{36}$ Lower percentages of PVL genes were found in Iowa and Nebraska populations with only $8 \%$ of $S$. aureus carrying PVL genes. ${ }^{2}$ MRSA isolates in this study showed higher frequency of PVL genes, 33\%, when compared to MSSA (19\%). Studies in Indonesia reported a high frequency of PVL genes, $10.6 \%$, in MSSA isolates. ${ }^{35}$ However, nasal MSSA isolates from community health centers in the NY city area showed a PVL frequency of $30 \%{ }^{29}$

Higher frequency of PVL genes is a common marker for CAMRSA than HA-MRSA which usually showed less than $4 \%{ }^{9}{ }^{9,13,37}$ Studies in China and Australia reported low percentages of PVL genes in CA-MRSA, $11 \%$ and $0 \%$ respectively. ${ }^{3,38}$ Studies in Tennessee found a 93.6\% PVL positives among CA-MRSA. ${ }^{27}$ Shukla et al. ${ }^{9}$ demonstrated that the prevalence of PVL genes in CA-MRSA from the states of Minnesota and Wisconsin was $100 \%$. The healthy population we studied showed CA-MRSA strains with a very low PVL frequency, 27\%. Higher numbers were found in CA-MRSA isolates from a healthy Mexican population, ${ }^{28} 67 \%$.

Regarding the ACME gene, all type IV SCCmec strains in this study were positive with MRSA strains showing an overall frequency of $94 \%$. Percentage of ACME was also very high for MSSA strains with $53 \%$ showing a positive reaction. ACME was not highly prevalent in a Mexican population colonized by CA-MRSA. ${ }^{28} \mathrm{~S}$. aureus isolates from healthy Iranian populations showed lower numbers of ACME genes, $17 \%$. The ACME gene $(8.37 \%)$ was detected in MRSA strains from England and Wales isolated from skin and soft tissue infections. ${ }^{39}$ Out of $104 \mathrm{~S}$. aureus isolated from wounds and nasal samples in Community Health Centers in the NY City metropolitan area, ACME was present in all USA300 strains. ${ }^{29}$

The presence of tst and sea genes can enhance the virulence of nasal $S$. aureus isolates. TSS is a condition characterized by fever, rash, and hypotension. In this study, MRSA isolates showed higher frequency of $t s t$ genes than MSSA. Previous studies reported a frequency of $24.3 \%$ from healthy carriers. ${ }^{8}$ Clinical S. aureus strains in Germany showed lower frequency of $t$ st genes with $20.3 \%{ }^{40} \mathrm{We}$ found a higher percentage, $27 \%$, among the $S$. aureus population analyzed in this study. However, Nagao et al ${ }^{41}$ reported a much higher percentage in Japanese clinical isolates with $75 \%$ of MRSA possessing the $t s t$ gene compared to $33 \%$ of the non-clinical MRSA isolates found in our study. A healthy student population in central Iran showed type IV SCCmec strains with a $28.5 \%$ prevalence. ${ }^{42}$ In this study, we found very similar abundance, $29 \%$, in type IV SCCmec strains.

Staphylococcal enterotoxins such as sea are the main cause of food poisoning by $S$. aureus causing intensive intestinal peristalsis. The sea numbers, $38 \%$, were much higher than the ones reported by previous analysis of healthy $S$. aureus nasal carriers. ${ }^{8}$ Analysis of Canadian and Dutch $S$. aureus isolates reported that only $19.6 \%$ were positive for sea. Clinical $S$. aureus strains in Germany showed lower percentages with only $15.9 \%$ of isolates from nasal and blood samples showing the presence of the sea gene. ${ }^{40}$ In our study, sea was the only gene along with tet $M$ found at higher frequencies in MSSA than in MRSA. However, studies of clinical isolates from China showed MRSA with higher numbers of sea than MSSA. ${ }^{34}$

\section{Conclusion}

In summary, $S$. aureus and MRSA isolated from a healthy suburban population exhibited a very high genotypic diversity based upon typing of the spa gene. However, most MRSA strains detected belonged to SCCmec type IV. Our data provide further evidence of the frequency of antimicrobial resistance and virulence genes indicating the distribution of potentially pathogenic strains among nonsymptomatic and healthy suburban populations which may represent a potential reservoir to disseminate these strains among susceptible populations. A possible limitation of our study was the sampling of only one nostril which may have underestimated the frequency of potential $S$. aureus and MRSA carriers.

\section{Acknowledgments}

None.

\section{Conflicts of interest}

Authors declare that there is no conflict of interest. 


\section{References}

1. Klevens RM, Morrison MA, Nadle J, et al. Invasive methicillinresistant Staphylococcus aureus infections in the United States. JAMA. 2007;298(15):1763-1771

2. Kildow BJ, Conradie JP, Robson RL. Nostrils of healthy volunteers are independent with regard to Staphylococcus aureus carriage. J Clin Microbiol. 2012;50(11):3744-3746.

3. Du J, Chen C, Ding, B, et al. Molecular characterization and antimicrobial susceptibility of nasal Staphylococcus aureus isolates from a Chinese medical college campus. PloS One. 2011;6(11):e27328.

4. Fard-Mousavi N, Mosayebi G, Amouzandeh-Nobaveh A, et al. The dynamic of Staphylococcus aureus nasal carriage in central Iran Jundishapur J Microbiol. 2015;8(7):e20760.

5. Sivaraman K, Venkataraman N, Cole AM. Staphylococcus aureus nasal carriage and its contributing factors. Future Microbiol. 2009;4(8):9991008 .

6. Datta R, Huang SS. Risk of infection and death due to methicillin resistant Staphylococcus aureus in long-term carriers. Clin Infect Dis. 2008;47(2):176-181.

7. Skr A, Bregeon F, Mege JL, et al. Staphylococcus aureus nasal colonization: An update on mechanisms, epidemiology, risk factors, and subsequent infections. Front Microbiol. 2018;9:2419.

8. Mehrotra M, Wang G, Johnson WH. Multiplex PCR for detection of genes for Staphylococcus aureus enterotoxins, exfoliative toxins, toxic shock syndrome toxin 1, and methicillin resistance. J Clin Microbiol. 2000;38(3):1032-1035.

9. Shukla SK, Karow ME, Brady JM, et al. Virulence genes and genotypic associations in nasal carriage, community associated methicillinsusceptible and methicillin-resistant USA400 Staphylococcus aureus. J Clin Microbiol. 2010;48(10):3582-3592.

10. Diep BA, Gill SR, Chang RF, et al. Complete genome sequence of USA300, an epidemic clone of community acquired methicillin-resistant Staphylococcus aureus. Lancet. 2006;367(9512):731-739.

11. Shopsin B, Gomez M, Montgomery SO, et al. Evaluation of protein A gene polymorphic region DNA sequencing for typing of Staphylococcus aureus strains. J Clin Microbiol. 1999;37(11):3556-3563.

12. Stegger M, Andersen PS, Kearns A, et al. Rapid detection, differentiation and typing of methicillin-resistant Staphylococcus aureus harbouring either mecA or the new mecA homologue mecA(LGA251). Clin Microbiol Infect. 2012;18(4):395-400.

13. Fey PD, Said-Salim B, Rupp ME, et al. Comparative molecular analysis of community or hospital-acquired methicillin-resistant Staphylococcus aureus. Antimicrobial Agents and Chemoteraphy. 2003;47(1):196-203.

14. Jimenez L, Jashari T, Vasquez J, et al. Real-Time PCR detection of Burkholderia cepacia in pharmaceutical products contaminated with low levels of bacterial contamination. PDA Journal of Pharmaceutical Science and Technology. 2018;72(1):73-80.

15. Saruta K, Hoshina S, Machida K. Genetic identification of Staphylococcus aureus by polymerase chain reaction using single-base-pair mismatch in 16S ribosomal RNA gene. Microbiol Immunol. 1995;39(11):839-844.

16. Azimian A, Havael SA, Fazeli H, et al. Genetic characterization of a vancomycin resistant Staphylococcus aureus isolate from the respiratory tract of a patient in a university hospital in northern Iran. $J$ Clinical Microbiol. 2012;50(11):3581-3585.

17. Strommenger B, Kettliz C, Werner G, et al. Multiplex PCR assay for simultaneous detection of nine clinically relevant antibiotic resistance genes in Staphylococcus aureus. Journal of Clinical Microbiology. 2003;41(9):4089-4094.
18. Altschul SF, Madden TL, Schaffer AA, et al. Gapped BLAST and PSIBLAST: a new generation of protein database search programs. Nucleic Acid Research. 1997;25(17):3389-3402.

19. Harmsen D, Claus H, Witte W, et al. Typing of methicillin-resistant Staphylococcus aureus in a university hospital setting by using novel software for spa repeat determination and database management. J Clin Microbiol. 2003;41(12):5442-5448.

20. Boyle K, Bartels MD, Andersen IS, et al. A new multiplex PCR for easy screening of methicillin-susceptible Staphylococcus aureus SCCmec types I-V. Clinical Microbiology and Infection. 2003;13(7):725-727.

21. Sharma Y, Jain S, Sing H, et al. Staphylococcus aureus: Screening for nasal carriers in a community setting with special reference to MRSA. Scientifica. 2014;2014:479048.

22. Eibach D, Nagel M, Hogan B, et al. Nasal Carriage of Staphylococcus aureus among Children in the Ashanti Region of Ghana. PLoS One. 2017;12(1):e0170320.

23. Lamaro-Cardoso J, de Lencastre H, Kipnis A, et al. Molecular epidemiology and risk factors for nasal carriage of Staphylococcus aureus and methicillin-resistant $S$. aureus in infants attending day care centers in Brazil. J Clin Microbiol. 2009;47(12):3991-3997.

24. Wertheitm HFL, Melles DC, Vos MC, et al. The role of nasal carriage in Staphylococcus aureus infections. Lancet Infect Dis. 2005;5(12):751-762.

25. Uhlemann AC, Know J, Miller M, et al. The environment as an unrecognized reservoir for community-associated methicillin-resistant Staphylococcus aureus USA300: A case-control study. PLoS One. 2011;6(7):e22407.

26. Muttaiyah S, Coombs G, Pandey S, et al. Incidence, risk factors, and outcomes of Panton-Valentine leukocidin-positive methicillin-susceptible Staphylococcus aureus infections in Auckland, New Zealand. J Clin Microbiol. 2010;48(10):3470-3474.

27. Kilic A, Li H, Stratton CW, et al. Antimicrobial Susceptibility Patterns and Staphylococcal Cassette Chromosome mec Types of, as well as Panton-Valentine Leukocidin Occurrence among, Methicillin-Resistant Staphylococcus aureus Isolates from Children and Adults in Middle Tennessee. J Clin Microbiol. 2006;44(12):4436-4440.

28. Hamdan-Partida A, Sainz-Espunez T, Bustos-Martinez J. Isolation of community-acquired methicillin-resistant Staphylococcus aureus in healthy carriers in a Mexican community. International Journal of Infectious Diseases. 2014;18:22-26.

29. Pardos de la Gandara M, Raygoza Garay JA, Mwangi M, et al. Molecular types of methicillin-resistant Staphylococcus aureus and methicillinsensitive Staphylococcus aureus strains causing skin and soft tissue infections and nasal colonization, identified in community health centers in New York city. J Clinical Microbiol. 2015;53(8):2648-2658.

30. Cheatham S, Thapaliya D, Taha M, et al. Prevalence of Staphylococcus aureus and methicillin-resistant $S$. aureus on environmental surface in Ohio nursing homes. Am J Infection Control. 2009;47(12):1415-1419.

31. Uhlemann AC, Dordel J, Knox JR, et al. Molecular tracing of the emergence, diversification, and transmission of Staphylococcus aureus sequence type 8 in a New York community. PNAS. 2014;111(18):67386743.

32. Emaneini M, Bigverdi R, Kalantar D, et al. Distribution of genes encoding tetracycline resistant and aminoglycoside modifying enzymes in Staphylococcus aureus strain isolated from a burn center. Annals of Burns and Fire Disasters. 2013;26(2):76-80.

33. Lina G, Quaglia A, Reverdy, ME, et al. Distribution of genes encoding resistance to macrolides, lincosamides, and streptogramins among Staphylococci. Antimicro Agents Chemother. 1999;43(5):1062-1066. 
34. Li X, Huang T, Li C, et al. Molecular characteristics and virulence gene profiles of Staphylococcus aureus isolates in Hainan, China. BMC Infectious Diseases. 2019;19(1):873.

35. Severin JA, Lestari ES, Kuntaman K, et al. Unusually high prevalence of panton-valentine leukocidin genes among methicillin-sensitive Staphylococcus aureus strains carried in the Indonesian population. J Clin Microbiol. 2008;46(6):1989-1995.

36. Lowy FD, Aiello AE, Bhat M, et al. Staphylococcus aureus colonization and infection in New York State prisons. J Infect Dis. 2007;196(6):911918.

37. Naimi TS, LeDell KH, Como-Sabetti K, et al. Comparison of communityacquired and health care associated Methicilin-Resistant Staphylococcus aureus infection. JAMA. 2003;290(22):2976-2984.

38. O'Brien FG, Lim TT, Chong FN, et al. Diversity among community isolates of Methicillin-Resistant Staphylococcus aureus in Australia. J Clin Microbiol. 2004;42(10):3185-3190.
39. Ellington MJ, Yearwood L, Ganner M, et al. Distribution of the ACMEarcA gene among Methicillin-Resistant Staphylococcus aureus from England and Wales. J Antimicrob Chemother. 2008;61(1):73-77.

40. Becker K, Friedrich AW, Lubritz G, et al. Prevalence of genes encoding pyrogenic toxin superantigens and exfoliative toxins among strains of Staphylococcus aureus isolated from blood and nasal specimens. J Clin Microbiol. 2003;41(4):1434-1439.

41. Nagao M, Okamoto A, Yamada K, et al. Variations in amount of TSST-1 produced by clinical methicillin resistant Staphylococcus aureus (MRSA) isolates and allelic variation in accessory gene regulator (agr) locus. $B M C$ Microbiol. 2009;9:52.

42. Japoni-Nejad A, Rezazadeh M, Kazemian H, et al. Molecular characterization of the first community-acquired methicillin-resistant Staphylococcus aureus strains from Central Iran. International Journal of Infectious Diseases. 2013;17(11):e949-e954. 